International Journal of Current Microbiology and Applied Sciences

ISSN: 2319-7706 Volume 6 Number 9 (2017) pp. 690-696

Journal homepage: http://www.ijcmas.com

Original Research Article

https://doi.org/10.20546/ijcmas.2017.609.084

\title{
Prevalence of Staphylococcus aureus and Methicillin Resistant Staphylococcus aureus from Milk and Milk Products in and around Srinagar Area of Kashmir, India
}

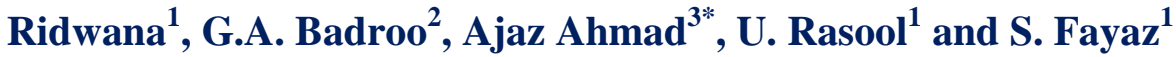 \\ ${ }^{1}$ Department of Food Technology, Doon Valley Institute of Engineering and Technology, \\ Karnal, Haryana, India \\ ${ }^{2}$ Department of Veterinary Microbiology, SKUAST-Jammu, India \\ ${ }^{3}$ Department of Veterinary Pathology, GADVASU, Ludhiana, Punjab, India \\ *Corresponding author
}

\section{A B S T R A C T}

The present study was focused on to determine the presence of $S$. aureus in

Keywords

Prevalence, Milk,

Staphylococcus aureus, MRSA.

Article Info

Accepted:

14 July 2017

Available Online:

10 September 2017 milk and milk products and also to determine the resistance against methicillin. During this study it was found that there was high presence of $S$. aureus as well as MRSA in milk and milk products (curd, cheese and ice-cream). Out of 130 isolates only $60(46.15 \%)$ samples were positive for S. aureus of which, $29(22.30 \%)$ were phenotypically MRSA. S. aureus prevalence in milk was 15/25 (60\%), 13/25 (52\%) and 6/10 (60\%) in cow, buffalo and goat respectively. Out of 34 S. aureus milk isolates, 15(44.1\%) were MRSA positive. Prevalence of S. aureus in curd was 12/30 (40\%), in cheese was $6 / 25$ (24\%) and in ice-cream was 8/15 (53.33\%). The presence of Staphylococcus aureus strains in milk and milk products needs special attention towards public health hazards.

\section{Introduction}

Raw milk is an ideal growth medium for several microorganisms. Milk and its derivatives are considered vehicles of Staphylococcus aureus for infection in humans (Zecconi and Hahn, 2000). S. aureus is an important foodborne pathogen and causes a wide variety of diseases in humans and animals, ranging in severity from a mild skin infection to more severe diseases, such as pneumonia and septicemia (Lowy, 1998). In dairy cattle, S. aureus is frequently associated with subclinical mastitis (Adesiyun et al., 1998) and may contaminate milk and other dairy products (Capurro et al., 1999).

S. aureus produces several staphylococcal virulence factors, including enterotoxins (SEA to SEE and SEG to SEQ), and other toxins, such as exfoliative toxin $\mathrm{A}$ and $\mathrm{B}$, and toxic shock syndrome toxin (TSST-1) (Fagundes and Oliveira, 2004). Staphylococcal food poisoning (SFP) is 
recognized as a cause of foodborne diseases (Jorgensen et al., 2005).

Mammary glands infected by $S$. aureus are the main cause of milk contamination (Jayarao et al., 2004). Contaminated milking equipment and the hands of the milkers are also common vehicles of transmission (Cullor, 1997). Although pasteurization kills $S$. aureus cells, thermostable SEs generally retain their biological activity. SFP risk related to pasteurized milk products may be minimized by adequate chilling of raw milk until heat treatment, followed by rigorous efforts to prevent recontamination (Jorgensen et al., 2005). The aim of present study was to investigate the incidence of $S$. aureus and presence of enterotoxins in strains isolated in raw milk.

\section{Materials and Methods}

The research work was carried out in the Division of Veterinary Microbiology, Faculty of Veterinary Sciences and Animal Husbandry, SKUAST, Jammu, Jammu and Kashmir. The period of study was from February 2017-April 2017(3 months). The milk samples were collected aseptically in pre-sterilized test tubes and other glassware and transported over ice within 2 hours of collection to the division for further processing and analysis.

Each sample was enriched in peptone water and incubated at $37^{\circ} \mathrm{C}$ for $24 \mathrm{hrs}$. Each inoculum was cultured on Baird Parker agar (selective medium for Staphylococcus aureus) and incubated at $37^{\circ} \mathrm{C}$ for $48 \mathrm{hrs}$. Then a single isolated colony was picked and streaked on mannitol salt agar and incubated at $37^{\circ} \mathrm{C}$ for $24-48 \mathrm{hrs}$ and further the organisms were identified on the basis of their cultural, morphological, staining and various biochemical characteristics. All positive samples were subjected to coagulase test for confirmation of $S$. aureus as described by Monica, 1991. Biochemical characterization of the presumptive $S$. aureus isolates was performed as described by Bennett and Lancette (2001). Thus, confirmed S. aureus isolates were inoculated and cultured on Oxacillin resistance screening agar (ORSA) for detection of Methicillin Resistant $S$. aureus (Pereira et al., 2009).

\section{Processing of samples for S. aureus and MRSA}

The isolation and identification of $S$. aureus isolates was carried by enrichment of samples in peptone water followed by incubation at $37^{\circ} \mathrm{C}$ for $24 \mathrm{hrs}$. Streaking of enriched inoculum on Baird-Parker (selective medium) and Mannitol Salt Agar followed by incubation at $37^{\circ} \mathrm{C}$ for $24-48 \mathrm{hrs}$. The presumptive pale-yellow colored friable colonies of $S$. aureus were inoculated in Brain Heart Infusion Broth and incubated at $37^{\circ} \mathrm{C}$ for $18-24 \mathrm{hrs}$ and stored in refrigerator for further processing. Biochemical identification of presumed $S$. aureus isolates. The confirmed $S$. aureus isolates were subjected to Disc diffusion antibiotic sensitivity test. The confirmed $S$. aureus isolates were inoculated and cultured on Oxacillin resistance screening agar (ORSA) for detection of Methicillin Resistance $S$. aureus. The presumptive blue colored colonies of MRSA on Oxacillin resistance screening agar were further inoculated in MRSA alert test kit for Methicillin Resistant $S$. aureus confirmation.

\section{Characterization of Staphylococcus isolates}

\section{Gram's staining}

All the presumed cultures of Staphylococcus spp. were subjected to Gram's staining and observed under a light microscope for Gram's reaction, size, shape and cell arrangements. The Gram-stained smears from typical 
colonies that showed Gram-positive cocci occurring in bunched grape like irregular clusters were taken as presumptive Staphylococcus species (Figure 1).

\section{Tube coagulase test}

$3 \mathrm{ml}$ sterile distilled water was added aseptically to rehydrate $0.1 \mathrm{gm}$ of rabbit coagulase plasma. $0.5 \mathrm{ml}$ of the rehydrated content was added to $0.05 \mathrm{ml}$ overnight broth culture of S.aureus. The tubes were incubated at $37^{\circ} \mathrm{C}$ for $4-6$ hours during which these were observed for clot formation which was taken as positive reaction for $S$. aureus.

\section{Biochemical characterization}

All the isolates were further subjected to series of biochemical tests which included Indole test, Methyl red test, Voges-Proskauer test and Citrate utilization test.

\section{Indole test}

This test was performed to demonstrate the ability to decompose the amino-acid tryptophan to indole. The test was performed by inoculating the test culture in 2 percent tryptone water, incubated at $37^{\circ} \mathrm{C}$ for 48 to 96 hours. Kovac's reagent $0.5 \mathrm{ml}$ was added to the culture medium and shaken gently. Appearance of Red colour indicated positive reaction.

\section{Methyl red test}

The test was performed by inoculating glucose phosphate broth with test organism and incubated at $37^{0} \mathrm{C}$

\section{Voges- Proskauer test}

The bacteria that ferment carbohydrates with the production of acetyl methyl carbinol or its reduction product 2,3 , butylene glycol can be tested by a colorimetric reaction between diacetyl (which is formed during the test by oxidation of acetyl methyl carbinol or 2, 3 , butylene glycol) and a guanidine group. $5 \mathrm{ml}$ of glucose phosphate peptone water (MR-VP Broth) Hi-Media Pvt. Ltd. was inoculated with isolated organism and incubated at $37^{\circ} \mathrm{C}$ for 48 hours. Then $1 \mathrm{ml}$ of 40 percent potassium hydroxide and $3 \mathrm{ml}$ of 5 percent $\alpha$ napthol in absolute ethyl alcohol were added. Change in colour to red indicated a positive reaction.

\section{Citrate utilization test}

Simmons's citrate medium was used to detect ability of the organism to utilize citrate as the sole source of carbon and energy for growth and an ammonium salt as the sole source of nitrogen. The test was carried out by inoculating Simmon's citrate media with test organism and incubating at $37^{\circ} \mathrm{C}$ up to $48-96$ hrs. Change in green solid slant to blue indicated a positive reaction for Staphylococcus.

\section{Catalase test}

On a single bacterial colony grown over nutrient agar plate, a loopful of 3 percent $\mathrm{H}_{2} \mathrm{O}_{2}$ was added. Prompt effervescence indicated catalase production confirming the test.

\section{Oxidase test}

In order to carry out this test oxidase discs were used. A loopful of colonies was rubbed over the moistened discs. No change in colour indicated negative reaction for Staphylococcus spp.

\section{MRSA detection}

The confirmed Staphyloccusaureus isolates were further inoculated on to Oxacillin Resistance Screening Agar. The medium 
incorporates an optimized salt level, lithium chloride and polymyxin B to suppress competing flora; aniline blue as an indicator dye for mannitol fermentation and oxacillin at a level of $2 \mathrm{mg} / \mathrm{l}$. The colonies that were blue in color were taken as presumptive MRSA (Figure 2).

\section{Results and Discussion}

Prevalence of MRSA in raw milk and milk products vis-a-vis the emerging threat of $S$. aureus and MRSA. Thus, more prevalence studies are required to generate data about occurrence $S$. aureus and MRSA in raw milk and milk products. Hence, a study of problem of $S$. aureus including MRSA with respect to its presence in raw milk and milk products was carried. One hundred ten (130) samples from milk and milk products were analysed.
These included 60 samples each from raw milk (cow-25, buffalo-25 and goat-10), 30 samples from curd, 25 samples from cheese and 15 samples from ice-cream. The samples were processed to reveal the prevalence of $S$. aureus and methicillin resistance using various techniques. Sixty (60) isolates of $S$. aureus were obtained and identified on the basis of cultural, morphological and biochemical characters. The isolates thus obtained were further processed to detect the prevalence of Methicillin resistant $S$. aureus (MRSA). The overall occurrence of $S$. aureus in milk and milk products was $46.15 \%$ with $60 \%, 60 \%$ and $52 \%$ in raw milk of cow, goat and buffalo respectively and $53.3 \%, 40 \%$ and $24 \%$ in the processed milk and milk products like ice-cream, curd and cheese respectively. The presence of MRSA in cow milk was $8 / 15$ $(32 \%)$.

Fig.1 Gram's staining showing characteristic violet colored grapes bunch like appearance

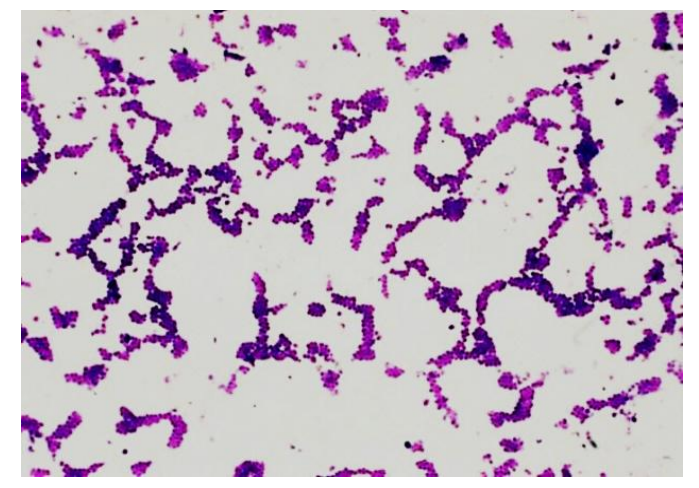

Fig.2 Characteristic deep blue colonies of Methicillin Resistant S. aureus (MRSA) on Oxacillin resistance screening agar media

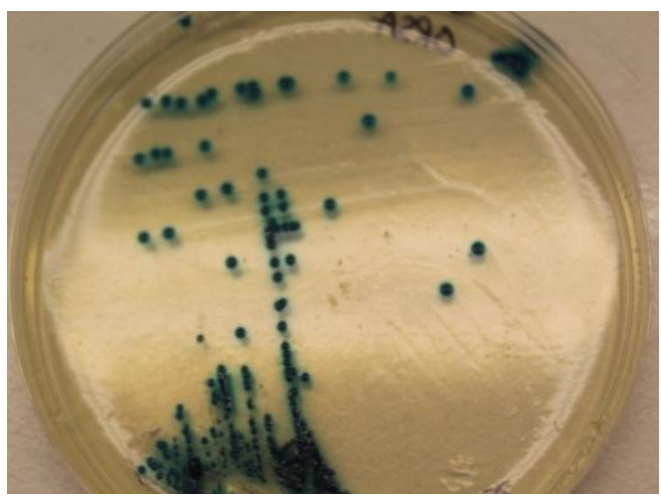


Fig.3 Characteristic yellow colored, friable colonies of $S$. aureus on Mannitol salt agar media

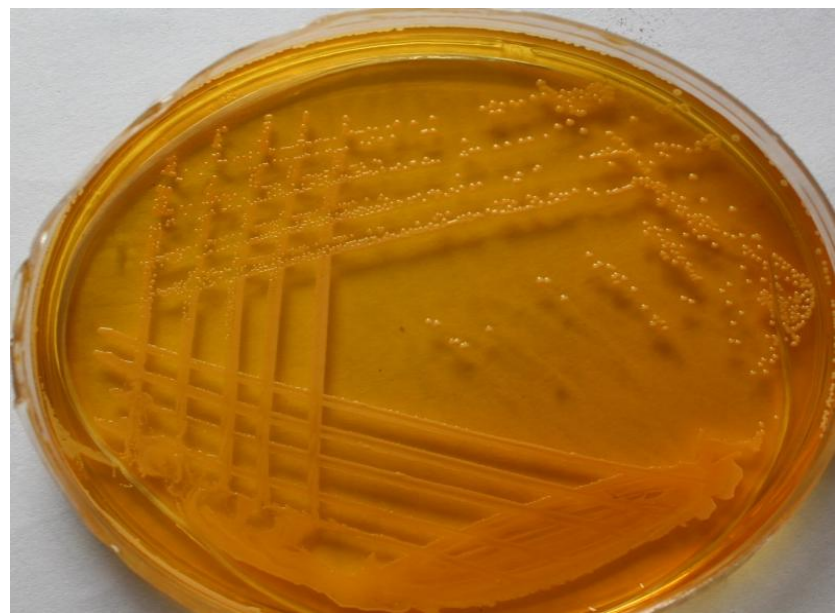

Fig.4 Jet black colonies of $S$. aureus surrounded by a light halo on Baird-Parker agar media

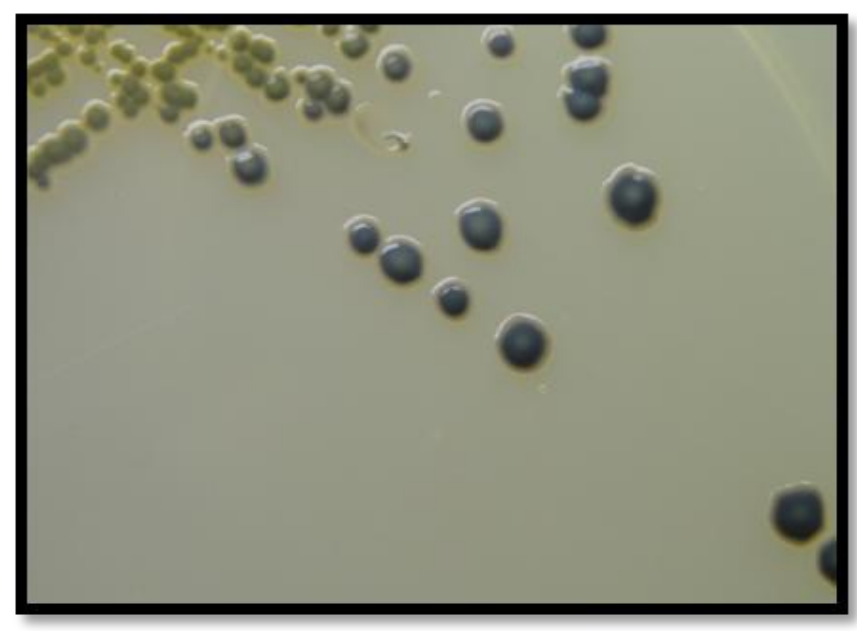

Fig.5 Characteristic effervescence shown by presumptive $S$. aureus colonies on catalase test

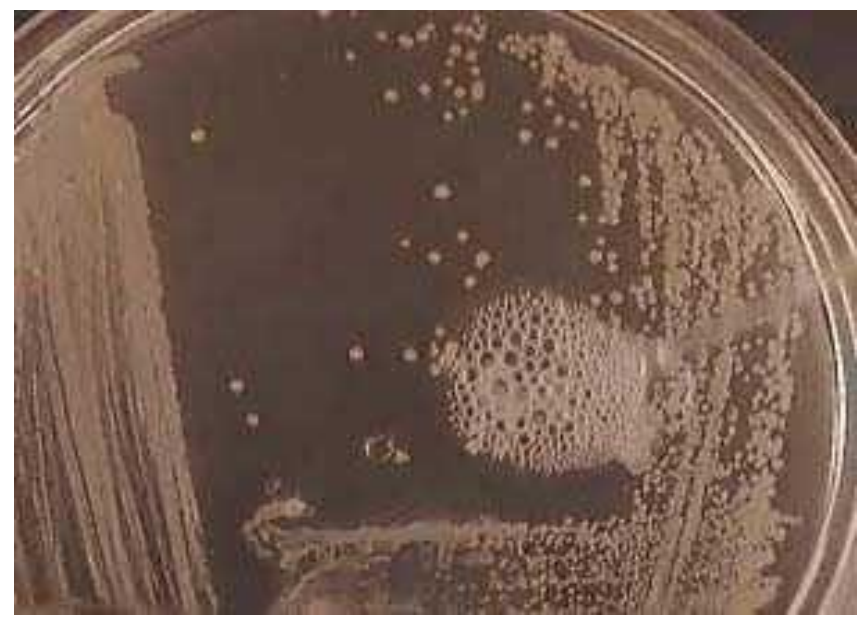


The buffalo and goat milk however, recorded much less per cent of MRSA. The buffalo milk showed 6/13 (24\%) and goat milk 1/6 (10\%) MRSA. The presence of MRSA in curd samples and cheese samples was recorded as $7 / 12$ and $4 / 6$ respectively (16\%) whereas $3 / 8(20 \%)$ in ice-cream samples.

The bacteriological quality of the samples was assessed by standard methods. Isolation and identification of $S$. aureus was carried out using specific biochemical media. All the isolates fermented mannitol, showed growth on Baird-Parker agar media (Figures 3 and 4). The isolates were catalase positive (Figure 5), oxidase negative, indole positive, MR-VP positive and coagulase positive following the methods as described by Monica (1991), the findings corresponded well with the findings of Singh and Prakash (2008). Coagulase production has generally been regarded as a specific property of pathogenic Staphylococci; the organisms may sometimes lose coagulase production ability due to various reasons (Baird-Parker, 1965). The work of health inspection in municipalities is crucial to raise consumer awareness on the consumption of good-quality milk through educational programs and the inspection of establishments that insist on selling raw milk. Dairy inspection and the adoption of good fabrication practices can also contribute to a reduction in contamination of pasteurized milk.

The counts of Staphylococcus aureus in milk analyzed indicate the product is improper for human consumption, and the population of Srinagar is vulnerable to toxic infections. The presence of Staphylococcus aureus in raw and pasteurized milk underlines the importance of preventive measures to ensure the quality of the milk from milking through to the processing in the dairy industry, in order to avoid the occurrence of pathogenic microorganisms and consequently to prevent risks of transport of toxic infections by the consumption of contaminated milk.

\section{References}

Adesiyun, A.A., Webb, L. A., Romain, H. T. 1998. Prevalence and characteristics of Staphylococcus aureus strains isolated from bulk and composite milk and cattle handlers. J. Food Prot., 61:629-632.

Baird-Parker, A.C., 1965. Staphylococci and their classification. Ann. N. Y. Acad. Sci., 128: 4-25.

Bennett, R.W., Lancette, G. A. 2001. Staphylococcus aureus. Chapter 12, Bacteriological Analytical Manual, United States Food and Drug Administration, Maryland.

Capurro, A., Concha, C., Nilsson, L., Ostensson, K. 1999. Identification of coagulase positive Staphylococci isolated from bovine milk. Acta Vet. Scand., 40:315-321.

Cullor, J.S., 1997.Risks and prevention of contamination of dairy products. Rev. Sci. Tech. Off. Int. Epiz., 16:472-481.

Fagundes, H., Oliveira, C.A. F. 2004. Infecçõesintramamáriascausadaspor Staphylococcus aureus esuasimplicaçõesem Saúde Pública. Cienc. Rural, 34:1315-1320.

Jayarao, B.M., Pillai, S. R., Sawant, A. A., Wolfgang, D. R., Hegde, N.V. 2004. Guidelines for monitoring bulk tank milk somatic cell and bacterial counts. J. Dairy Sci., 87:3561-3573.

Jorgensen, H.J., Mork, T., Hogasen, H. R., Rorvik, L. M. 2005.Enterotoxigenic Staphylococcus aureus in bulk milk in Norway. J. Appl. Microbiol., 99:158166.

Lowy, F.D., 1998.Staphylococcus aureus infection. N. Engl. J. Med., 339:520532.

Monica, C., 1991. Medical Laboratory manual for Tropical countries, 11: 60- 
63.

Pereira, V.C., Martins, A., Rugolo, L. M. S. S. and Cunha, M. L. R. S. 2009. Detection of Oxacillin Resistance in Staphylococcus aureus Isolated from the Neonatal and Pediatric Units of a Brazilian Teaching Hospital. Clinical Medicine Insights: Pediatrics, 3: 23-31.
Escherichia coli, Staphylococcus aureus and Listeria monocytogenes from milk products sold under market conditions at Agra region. Actaagriculturae Slovenica, 92: 83-88.

Zecconi, A., Hahn, G. 2000. Staphylococcus aureus in raw milk and human health risk. Bull. IDF, 345:15-18.

Singh, P., Prakash, A. 2008. Isolation of

\section{How to cite this article:}

Ridwana, G.A. Badroo, Ajaz Ahmad, U. Rasool and Fayaz, S. 2017. Prevalence of Staphylococcus aureus and Methicillin Resistant Staphylococcus aureus from Milk and Milk Products in and around Srinagar Area of Kashmir, India. Int.J.Curr.Microbiol.App.Sci. 6(9): 690-696. doi: https://doi.org/10.20546/ijcmas.2017.609.084 